\title{
Hybrid treatment of the infected carotid-subclavian graft complicated by the septic haemorrhage
}

\author{
Waldemar Macioch', Jerzy Leszczynski', Andrzej Kosicki', Tomasz Ostrowski', \\ Tomasz Brzezinski', Rafal Maciag', Maciej Skorski', Zbigniew Galazka' \\ 'Clinic of General and Endocrinological Surgery, Medical University of Warsaw, Poland \\ ${ }^{2}$ Second Department of Clinical Radiology, Medical University of Warsaw, Poland
}

\begin{abstract}
The paper presents combined method of treatment to 90-year-old female, admitted with the hemorrhage from the chronic purulent fistula in her left neck in the incision post left carotid to subclavian artery bypass in 1971. In the vascular center where she was operate on (outside of Poland) it was suggested, that she should undergo graft excision because of the possibility of graft blow and subsequent exsanguinations as the most severe complication but finally she gave up. In the new circumstances, in the face of no-indirect threat to life, there was urgent need for surgical treatment. Being aware of multiple risk factors from age, general condition and changes in local, developed the concept of radical, yet more saving, to-step procedure. At first by percutaneous means covered stents were implanted into the places of vascular anastomoses, followed by angioplasty of the narrowed origin of left subclavian artery. In the second phase, after a few days, the infected prosthesis was excised and the cavities in the arterial walls of the two arteries were provided. Before, during and after surgery targeted antibiotics were used with classic antiplatelet therapy regimen. Post-operative course was uneventful. The wound healed properly. Which currently consisting of 93 years, as for her age, she in excellent condition overall. There were no signs of infection recurrence observed.
\end{abstract}

Key words: prosthetic vascular graft infections, endograft/stentgraft infections, septic hemorrhage

Acta Angiol 2015; 21, I: II-15

\section{Introduction}

Every haemorrhage, regardless of the etiology, has pathological conditioning. Usually it is an urgent condition because it can cause actual death risk. Haemorrhages are not exceptional in the vascular surgery. Haemorrhages of different sizes occur during almost every vascular surgery, and the haemorrhagic postoperative complications are not unusual as well. Instant decisions and ability to cope with difficult situations often save a patient's life [1-4].

The septic haemorrhage as the postoperative complication after the artery reconstruction surgery is a particular condition because usually it affects patients in serious condition often after systemic infection and serious blood loss. The severity of the situation is completed by the fact that the coronary changes have a multifocal nature, by the coexistence of multiple other conditions and in general by the history of undergoing multiple artery reconstruction surgeries. Only as an exception, the haemorrhage occurs suddenly as the first symptom of an infection going on for a long time but with little symptoms [2-6].

In the infections of grafts located superficially, making the diagnosis and taking adequate strategy usually is not very difficult. The haemorrhages from the periphe- 
ral arteries considering the blood losses are not very heavy and their location allows early diagnosis and fast staunching, simply with applying pressure. They threat the limb but not a patient's life. However, also in the event of those haemorrhages, delaying the treatment can risk tragic consequences [1, 3, 7].

For obvious reasons haemorrhages from major arteries, especially deeply set (aorta, iliac arteries, subclavian arteries), are heavier and harder to control. Their treatment is complicated and often it has to be performed immediately. So it does not come as a surprise that they cause high mortality $[1,8]$.

The septic haemorrhages are characterised by different treatment. Because along with stopping the blood flow, usually complete excision of the infected synthetic material and difficult repair surgery, preferably with the usage of biological material has to be considered. Other circumstances additionally stress the importance of the problem: technical difficulties resulting from chronic inflammation and infiltration with proliferative reaction in the region of the infected prosthesis, often necessity of performing sudden and very complicated vascular reconstruction by random surgical team, haemorrhagic shock and often septic state with disturbance of the homeostasis and multisystem organ failure $[1,3,6,9]$.

New possibilities in the treatment of haemorrhages has been added by the intravascular techniques. The value of this techniques in the bursts of aneurysm or separations is well established, commonly accepted and cannot be overestimated. However, their usage in the septic haemorrhages can give rise to certain controversies. The idea of deliberate insertion of the next artificial material into the infected environment with low resistance to colonisation is disputable [14].

As the part in the discussion on the sense of such approach, the authors wish to present especially interesting history of a patient whose condition, age and the type of the changes forced less invasive treatment, ending in full success.

\section{Case study}

90 years old patient was admitted to the Clinic as an urgent case due to haemorrhage from the injury in the scar after carotid-subclavian bypass performed a long time ago. The patient estimated the loss of blood at about "two glasses". In the Clinic blood loss was not observed. It occurred in this scale for the first time. The purulent fistula on the neck occurred 5 years earlier. At first it was only a little leak of serum matter and then pus from a small opening in the middle of the scar above the left clavicle. Over time the opening of the fistula gotten bigger. At its bottom vascular prosthesis appeared and periodically minute amounts of blood was found. The patient was under the care of the

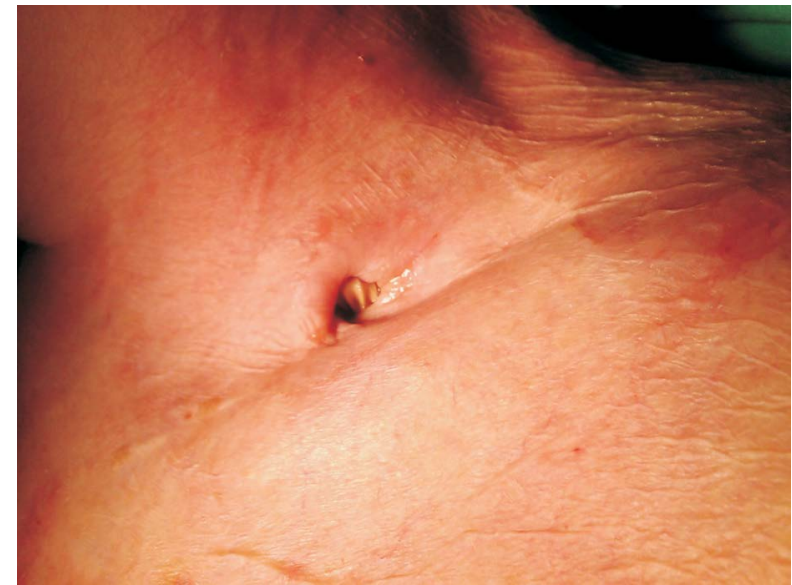

Figure I. Fistula in the scar on the neck with visible vascular prosthesis in the bottom of the wound

Vascular Clinic where the dressings were changed and bacteriological status was monitored (Fig. I).

Implantation of the carotid-subclavian bypass was performed due to the left subclavian artery steal syndrome in 197I in the USA where at that time patient lived permanently. The available documentation indicated that after the surgery early thrombosis of the vascular graft occurred and it was necessary to perform immediate reconstruction of the grafted system. For next 35 years of staying abroad and after returning to Poland nothing disturbing occurred.

The fistula appeared without any obvious connection to any certain situation. Due to lack of progress in the healing process the patient came to the Clinic in which years ago the first surgery was performed. After returning to Poland she was still treated conservatively until the day when the haemorrhage occurred.

From the beginning of hospitalisation it was known that further conservative actions are doomed to fail and occurrence of the next haemorrhage is a matter of time and probably not a long time. That is why planning of the surgical treatment was started strait away the idea of which was to remove the infected vascular prosthesis and safe restoration of the blood flow to the brain and left upper limb. Due to elderly age, not very good general condition (renal failure in III stadium, hypertension, type 2 diabetes), inflammatory infiltration spreading to the common carotid artery, subclavian artery and the vascular prosthesis visible in the computerized tomography scan, a less invasive approach was considered (Fig. 2).

Preparation to the surgery was short due to the circumstances. General empiric antibiotic treatment was started immediately and right after receiving the results of the culturing the treatment was targeted with two drugs. From the considered propositions, hybrid approach was chosen, considering it was effective-enough 


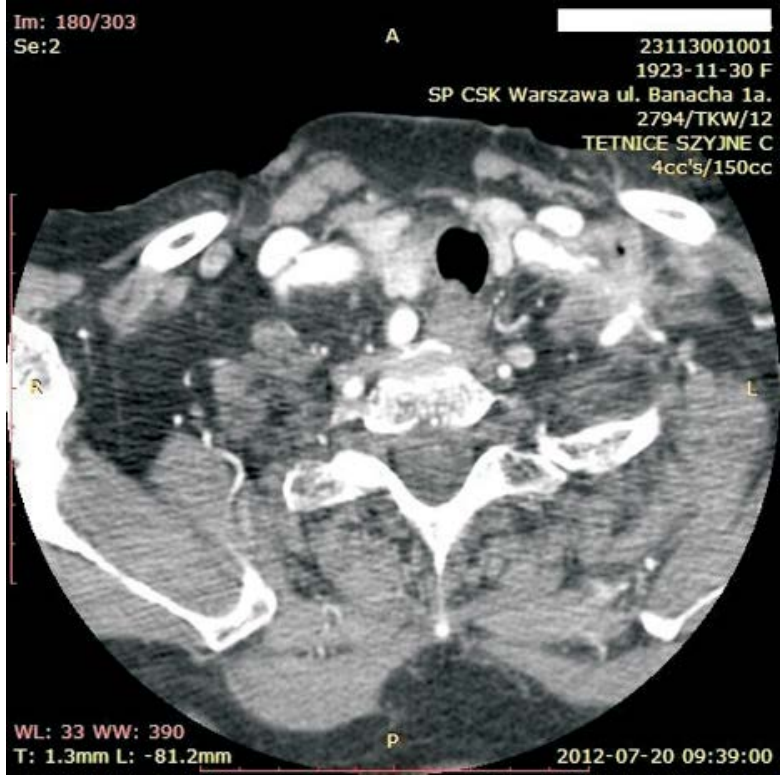

Figure 2. The spiral computed tomography. The arrow indicates the fistula and inflamed infiltration embracing the vascular prosthesis, and the carotid and subclavian artery

but first of all definitely less risky. The plan assumed two stages of the treatment. The first stage comprised of implantation of the covered stent to the common carotid artery and subclavian artery with angioplasty of the narrowed origin of the subclavian artery, and the second stage was the excision of the graft and providing the cavities in the arteries' walls.

During the intravascular stage, according to the plan, covered self-expanding stents were implanted in the places of anastomoses of vessels i.e. to the left common carotid artery (ATRIUM ADVENTA $8 \times 38 \mathrm{~mm}$ + PROTEGE GPS $9 \times 60 \mathrm{~mm}$ ) and the subclavian artery (ATRIUM ADVENTA $7 \times 38 \mathrm{~mm}+$ EVERFLEX $8 \times$ $40 \mathrm{~mm}$ ). Also successful bariatric angioplasty of the left subclavian artery using the stent GENESIS $7 \times 18 \mathrm{~mm}$ was carried out (Fig. 3).

While administrating the general and local antibiotic treatment of known effectiveness during the whole time, after 4 days, the surgical treatment was started. Brief surgery report is described below.

Arcuate cut above the left clavicle with excising the purulent fistula was performed. The coagulated, dacron vascular graft was separated. The prosthesis defibered and tattered when pulled. In its vicinity a large amount of necrotic tissues and infected granulation occurred. Carefully prepared, the interior carotid artery was separated and then anastomosis of the graft with the common carotid and subclavian arteries was performed. The place where during the first re-surgery 40 years ago a second reconstruction was performed was also found. The cause of the haemorrhage could have been the leakiness of the anastomosis

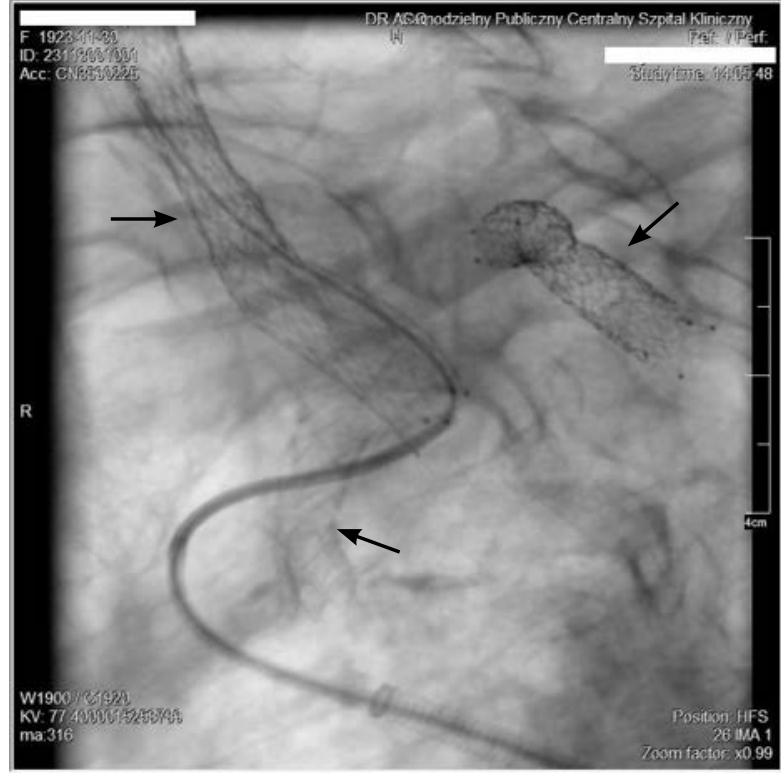

Figure 3. The state after the implantation of stents: in the origin of the subclavian artery (lower arrow) and covered in locations of anastomoses of the prosthesis with the common carotid and subclavian arteries (upper arrows)

in the area of the second surgery (probably shortening the too long prosthesis). Also the largest inflammatory infiltration was visible there. The next possible reason could have been the disintegration of the material structure and losing the physical properties of the prosthesis. The attempt to fully isolate the stem of the vagas and phrenic nerve among the infiltration failed. The graft was entirely removed. Blood leaking from the arteries' walls defects was not observed. In the possible range, tissues showing reactive changes were resected. In the vicinity of the malleolus medialis of the right lower limb a 6-cm section of the great saphenous vein was collected to construct patches to implant the arteries. When it turned out that the attempt of implanting them risks the endograft to leak, the plan was abandoned. The spots of anastomoses were carefully covered with surrounding tissues in such a way so there would not be any direct contact of the stentgraft with the abscess pocket. The wound was profusely rinsed with octenisept. On the bottom, the Garamycin sponge $200 \mathrm{mg} / 100 \mathrm{~cm}^{2}$ was spread and it was drained with closed method of Redon I6F. The top fasciocutaneous flap was modelled in a way allowing to stitch the edges without excessive tension. Layered closure.

The blood loss did not exceed $100 \mathrm{~mL}$. After the surgery no phonation nor breading disorders were observed.

After the procedure no complications were observed. The wound healed by primary healing. For another 2 weeks parenteral antibiotic treatment was continued. The patient was dismissed from the Clinic in good condition with recommendation of oral admission 
of antibiotics for next 4 weeks and two-drug anti-aggregation treatment for at least 6 months.

Three years from the surgery no signs of recurrence of the infection are present, the wound is healed and the general state of the patient is satisfactory.

\section{Description and discussion}

Infections of the vascular prostheses are among the most dangerous complications of the reconstructive treatments of the arteries. Fortunately, they occur rarely, in 0.5 to $5 \%$ of the surgically treated patients with the synthetic material. The most often it concerns the anastomoses in the groin, however, can become apparent in every vascular area. Infections after reconstructions of large vessels occur more rarely ( $<3 \%$ ) but the mortality connected to them is very high (>20\%). It is assumed that the cause of them, especially when they appear early, is a contamination during the surgical procedure, the most often from the skin, bowels or already existing foci of infection, even in distant location. Late infections can be a result of blood-related colonisation or spreading the infection through lymphatic system [I, 5, 7].

It is believed that the problem of septic complications will increase because the demand for the surgical treatments is increasing, as well as the proportion of patients diagnosed with diabetes in which the risk of infection is higher, the resistance of bacteria, the problem of atherosclerosis, and additionally, the societies grow old [5].

The main rule of treating the infections of the vascular prostheses is complete excision of the synthetic material. Usually, initially undertaken attempts of conservative treatment rarely end up with a success. Similarly to the small "cosmetic" procedures with rinsing or hypotension drainage or limited resections of infected prosthesis that leads to full recovery only in part of patients. For the full recovery to occur, special conditions need to take place i.e. elevated resistance of the material, low malignancy of bacteria, and active immunological response of the organism $[1,3,5,7,10,1 \mathrm{I}]$.

Infection of the endograft is definitely a lesser clinical problem. They occur less often, however, this does not mean never. According to statistics they affect less than $1 \%$ of surgeries more often carried out in the radiological facilities. A lot of authors emphasise the need of staying aware that the risk of endograft infection is still real. Thus, the recommendations of natural need of keeping sterile conditions of implantation and the necessity of applying antibiotic prophylactics, especially in cases of re-intervention and operations performed in radiological facilities. Early diagnosis and implementation of appropriate treatment is also important because the chance of full recovery increases $[13,14]$.
Treating the infected endografts is basically similar to the infections of vascular prosthesis. Conservative treatment is recommended in early stage of symptoms and in elderly patients with high risks. Lack of effects and the complications, especially in patients with better prognoses, is an indication to conventional treatment i.e., removing the endograft and restoration of blood flow with different methods [I, I3-18].

Van den Berg described the infection of stentgraft in a year from grafting in a patient, who had serious urological problems. When the conservative treatment did not give any results, endograft was finally removed after performing extra-anatomical bypasses. Other authors presented the case of infected stentgraft treated successfully with conversion to classic surgery i.e. after removing it, restoring the blood flow using dacron graft saturated with rifampicin which was additionally "wrapped" with omental apron [1, 5, 19].

The authors remember a patient who because of an aortoduodenal fistula after reconstruction of aorta was treated by implantation of the stentgraft with the intention of immediate stopping of the haemorrhage and preparing to the planned surgery of removing the infected vascular prosthesis. This patient did not express his consent to the radical treatment. Despite long-term antibiotic treatment, the patient died 5 months later, due to the next haemorrhage.

Starting the treatment of a patient from the beginning we were convinced that conventional procedure exceeds the reasonable risk limits. Thus the idea of small but at the same time, out of necessity, radical operation. It became apparent that the infection of the vascular prosthesis complicated with the septic haemorrhage requires graftectomy. The idea of the plan was to combine the tactics and although using next synthetic material but in an environment already without the infected prosthesis with high concentration of antibiotic of appropriate dependence, and with the long-term general antibiotic treatment. Our intention was to eliminate the uncontrolled haemorrhage and brain and limb ischaemia during technically difficult reconstruction and restoring the blood flow after removing the prosthesis. The plan was supposed to minimise the high risk of complications. Hybrid treatment completely met the expectations.

\section{Summary}

Controversial in the context of active infection, introducing new synthetic material of low resistance into the infected environment, cannot be evaluated as an experiment or act of despair. The authors think (by the way it is not an exceptional opinion) that in the certain group of patients this approach is by far justified. 
And even though the concept alone can rise doubts, the positive result of the treatment combined in such a way is a good argument confirming the advisability of this approach. The special significance of this strategy is visible in patients with high risks of conventional treatment and not very good life expectancy prognosis. In the opinion of authors the secret of the success, except for successful debridement and increased duration of antibiotic treatment, lies also in the favourable chain of circumstances.

The authors have not found similar description of hybrid treatment of vascular prosthesis infection in the literature, although the usage of endografts in haemorrhages from fistula between aorta and bowels or bronchi reached a lot of publications and pragmatic evaluations.

\section{References}

I. Yamanouchi D (ed) (20I2) Vascular surgery — principles and practice. Chapter 3, InTech.

2. Russu E, Muresan A, Grigorescu B (20II) Vascular graft infections. Management in Health; XV: 16-19.

3. Zetrenne E, Mclntosh BC, McRae BC et al (2007) Prosthetic vascular graft infection: a multi-center review of surgical management. Yale J Biol Med.; 80: II3-121.

4. Pupka A, Skóra J, Pawłowski S et al (2003) Operacyjne leczenie przetok aortalno-dwunastniczych po zabiegach rekonstrukcyjnych na aorcie brzusznej. Chir. Pol.; 5: 83-90.

5. Hasse B, Husmann L, Zinkernagel A et al (2013) Vascular graft infections. Swiss Med Wkly; 143: w 13754.

6. Saleem BR, Meerwaldt R, Tielliu IF et al (2010) Conservative treatment of vascular prosthetic graft infection is associated with high mortality. Am J Surg; 200: 47-52.
7. Gabriel M, Oszkinis G, Stanišić M et al (2006) Miejscowe zabiegi chirurgiczne $w$ leczeniu zakażonych protez naczyniowych analiza 64 przypadków. Acta Angiol; 12: 167-179.

8. Treska H, Houdek K, Vachtowa M et al (2008) Management of the prosthetic vascular graft infections - the influence of predictive factors on treatment results. Bratisl Lek Listy; 109: 544-550.

9. Wojciechowski J, Halena G, Trenkner M et al. (2005) Zastosowanie żyły udowej powierzchownej oraz pomostów pozaanatomicznych w leczeniu zakażeń protez naczyniowych. Acta Angiol; II: 50-60.

10. Herscu G, Wilson SE (2009) Prosthetic infection: lessons from treatment of the infected vascular graft. Surg Clin N Am; 89: 39I-40I.

II. Antoniou GA, Koutsias S, Antoniou SA et al (2009) Outcome after endovascular stent graft repair of aortoenteric fistula: a systematic review. J Vasc Surg; 49: 782-789.

12. Hart P, Eginton MT, Brown KR et al (2005) Operative strategies in aortic graft infections: is complete graft excision always necessary? Ann of Vasc Surg; 19: 154-160.

13. Sharif MA, Lee B, Lau LL et al (2007) Prosthetic stent graft infection after endovascular abdominal aortic aneurysm repair. J Vasc Surg. Sep; 46: 442-448.

14. Lichtenfels E, Delduque AF, Cardozo MA et al (201 I) Stent graft infection. J Vasc Bras.; 10: 50-54.

15. Setacci C, De Donato G, Setacci K et al (2010) Management abdominal endograft infection. J Cardiovasc Surg; 5I: 33-4I.

16. Heyer KS, Modi P, Morasch MD et al (2009) Secondary infections of thoracic and abdominal aortic endografts. J Vasc Interv Radiol; 20: 173-179.

17. Piffaretti G, Rivolta N, Mariscalco G et al (2010) Aortic endograft infection: a report of 2 cases. Int J Surg; 8: 216-220.

18. Hulin SJ, Morris GE (2007) Aortic endograft infection: open surgical management with endograft preservation. Eur J Vasc Endovasc Surg; 34: 191-193.

19. Van den Berg R, Leijdekker V, Vahl A (2006) Aortic stent-graft infection following septic complications of a kidney stone. Cardiac Vasc Interv Radiol; 29: 443-445. 